\title{
Redução de horas paradas na etapa de granulação: um estudo de caso da obstrução da calha de descarga do granulador
}

Jaziel Rosa Gonçalves Centro de Ensino Superior de Catalão (CESUC), Goiânia, Goiás, Brasil

Mara Rúbia da Silva Miranda mara_miranda20@yahoo.com.br Centro de Ensino Superior de Catalão (CESUC), Goiânia, Goiás, Brasil

\begin{abstract}
RESUMO
A busca pelo aumento de produtividade e a constante melhoria do processo têm sido foco de grandes empresas para se manterem no mercado. Diante disto, as diversas organizações procuram otimizar seus processos aplicando melhorias que podem ser pequenas, mas que no final auxiliam nas metas da empresa. Neste contexto, o objetivo deste estudo é mostrar que com a diminuição de horas paradas por obstrução da calha do granulador, tem-se ganhos de produção na unidade de granulação, maior continuidade operacional que é fundamental em uma fábrica de fertilizante e consequentemente menores descontroles operacionais durante o processo produtivo. A ideia do presente estudo surgiu a partir da análise da quantidade de horas paradas por obstrução da calha de descarga do granulador. A partir da análise das horas paradas, observação em campo dos problemas causados pela obstrução da calha foi possível traçar ações para eliminar/mitigar este problema. A obstrução da calha causava alguns problemas, como a perda de produção e descontinuidade operacional. No estudo realizado, as ações tomadas foram muito eficazes, reduzindo as horas paradas, elevando ganhos em produção e diminuições de perdas após a implementação das mesmas. É muito importante observar também que a melhoria realizada trouxe além de ganhos operacionais, também ganhos para os trabalhadores em qualidade de vida pela diminuição do trabalho manual desgastante. A unidade de granulação passou a operar com uma continuidade operacional muito superior nos períodos observados.
\end{abstract}

PALAVRAS-CHAVE: Produtividade. Fertilizantes. Granulador. 


\section{INTRODUÇÃO}

Com o aumento cada dia mais da população mundial, também se tem diretamente ligado a isso o aumento do consumo de alimentos. Aliado a isso há a necessidade do aumento da produção de alimentos para suprir esta necessidade. É aqui que entra a importância da fabricação de fertilizantes que a cada dia mais são utilizados na produção de alimentos.

Uma vez que o aumento das áreas de plantio é limitado e não conseguirá atender à demanda mundial de alimentos a manutenção e ampliação da produção agrícola somente poderá ser alcançada frente ao uso de fertilizantes nas plantações (2․ Congresso Brasileiro de Fertilizantes, 2012).

A indústria de fertilizantes então tem um importante papel, produzir cada vez mais para suprir o aumento dessa demanda. Hoje existem basicamente dois tipos de fertilizantes, em pó e o fertilizante granulado. O fertilizante granulado é o mais utilizado pela sua facilidade de aplicação nas lavouras, bem como menor empedramento e utilização nas máquinas de adubação.

Para a fabricação de fertilizantes granulados, os mesmos são produzidos em uma unidade de granulação, onde o granulador é considerado o coração de uma fábrica de fertilizantes, pois é no granulador onde acontecem as reações e a formação dos grânulos.

O presente trabalho irá abordar o processo de granulação, como este funciona e sua importância na fabricação de fertilizantes. Também irá mostrar em uma empresa como as perdas de um processo produtivo quando são mensuradas e analisadas podem ser reduzidas ou eliminadas.

As empresas hoje, em um modo geral tentam produzir sempre mais reduzindo seus custos. Os engenheiros e equipe de engenharia das empresas trabalham incansavelmente para a redução de custos e aumento de produtividade ou redução de perdas no processo produtivo.

Com a redução de perdas em qualquer processo se tem ganhos na produção, ganhos na produtividade e aliado a isso aumento de lucro e permanência em um mercado cada vez mais competitivo.

É extremamente necessário hoje as empresas otimizarem seus processos produtivos. O mercado nacional e internacional obriga de forma direta ou indiretamente as mesmas a tratarem seus desperdícios e perdas continuamente para se tornarem competitivas e com isso terem um aumento no lucro, foco principal e essencial para os acionistas e donos de qualquer empresa.

Neste contexto o presente trabalho irá mostrar o ganho de produção de fertilizantes obtido em 2016 em função da redução de horas paradas, comparando com ano de 2015. Através das análises dos processos, avaliação das perdas foram definidas ações para resolver ou mitigar os problemas avaliados.

Foram realizadas várias verificações para observar onde se tinham maiores perdas ou descontrole operacional. Através destas análises, observou-se que a obstrução da calha de descarga do granulador causava várias paradas e estas um descontrole operacional muito grande durante o processo de fabricação do fertilizante granulado. 
Então, através destas observações, análises de gráficos e perdas, foi verificado que havia a necessidade de um trabalho para eliminar ou mitigar estes problemas.

\section{REFERENCIAL TEÓRICO}

Hoje existe uma grande quantidade de pessoas que vivem no planeta Terra, diversas culturas, diferentes tipos de valores, pessoas que estão distribuídas em vários continentes, mas todas com algumas necessidades em comum, como o de viver e de se alimentar bem.

No caso da alimentação, a indústria de fertilizantes tem um papel cada vez mais importante na economia global. Com o crescimento da população aumentando a cada dia tem-se a necessidade de produzir mais alimentos com isso o aumento da produção de fertilizantes para manter a produção dos alimentos é essencial.

Então, para um melhor entendimento é necessário definir o que seria fertilizante. Fertilizantes é uma substância mineral ou orgânica, natural ou sintética, fornecedora de um ou mais nutrientes para as plantas, (BRASIL, 2004, p.02).

Os fertilizantes são compostos por três nutrientes básicos: nitrogênio (N), fósforo $(P)$ e potássio (K). Para que ocorra esse complemento, os mesmos são misturados conforme a necessidade do solo através de estudos agronômicos, para garantir uma melhor produção com menores gastos.

Segundo Soares (2008, p.10).

O fósforo $(P)$ atua na fotossíntese, respiração e transferência de energia, divisão celular, crescimento das células e em vários outros processos da planta. Além de promover a formação e crescimento prematuro das raízes, o fósforo melhora a qualidade de muitas frutas e verduras, sendo vital para a formação de sementes e maturação de frutos.

O Nitrogênio também tem uma influência muito grande nas plantas, estes de acordo com Ferreira (1997, apud SOARES, 2003, p.02).

O nitrogênio é um dos nutrientes que tem mais interferência nas características das plantas relacionadas ao crescimento e desenvolvimento, as quais, direta ou indiretamente afetam a produtividade.

Dentro destas definições, a produção de fertilizantes $\mathrm{N}, \mathrm{P}$ (Nitrogênio e Fósforo) são de extrema importância para o desenvolvimento do país. O nutriente $\mathrm{K}$ (potássio), não será abordado, visto que na produção do fertilizante 03-17-00 e 00-21-00, que são fertilizantes de baixa concentração o mesmo não é utilizado, este, é incorporado para o consumidor final nas fábricas misturadoras de fertilizantes.

O processo de fabricação de fertilizantes, embora sendo muito simples têmse complicações que afetam diretamente a produtividade, consequentemente ao lucro e competitividade da empresa no mercado nacional e global. Estas 
complicações podem ser em alguns casos de fácil resolução ou também gerar várias ações para que as mesmas sejam resolvidas.

Para a produção de fertilizantes $(\mathrm{N}, \mathrm{P})$, ou também conhecidos como superfosfatos, ou fertilizantes de baixa concentração são produzidos através da reação da rocha fosfática com ácidos sulfúrico ou fosfórico, (RODRIGUES, 2002, p.01).

Sendo o principal objetivo do processo de fabricação de superfosfatos fazer a conversão do fósforo contido na rocha fosfática em formas mais solúveis para as plantas. Esta conversão é realizada a partir da reação entre o ácido sulfúrico, rocha fosfática e água, gerando o SSP (Superfosfato Simples), matéria prima para a produção dos fertilizantes granulados 00-21-00 e 03-17-00. O superfosfato simples é produzido conforme Figura 1.

Figura 1 - Fluxograma do processo de produção de superfosfato

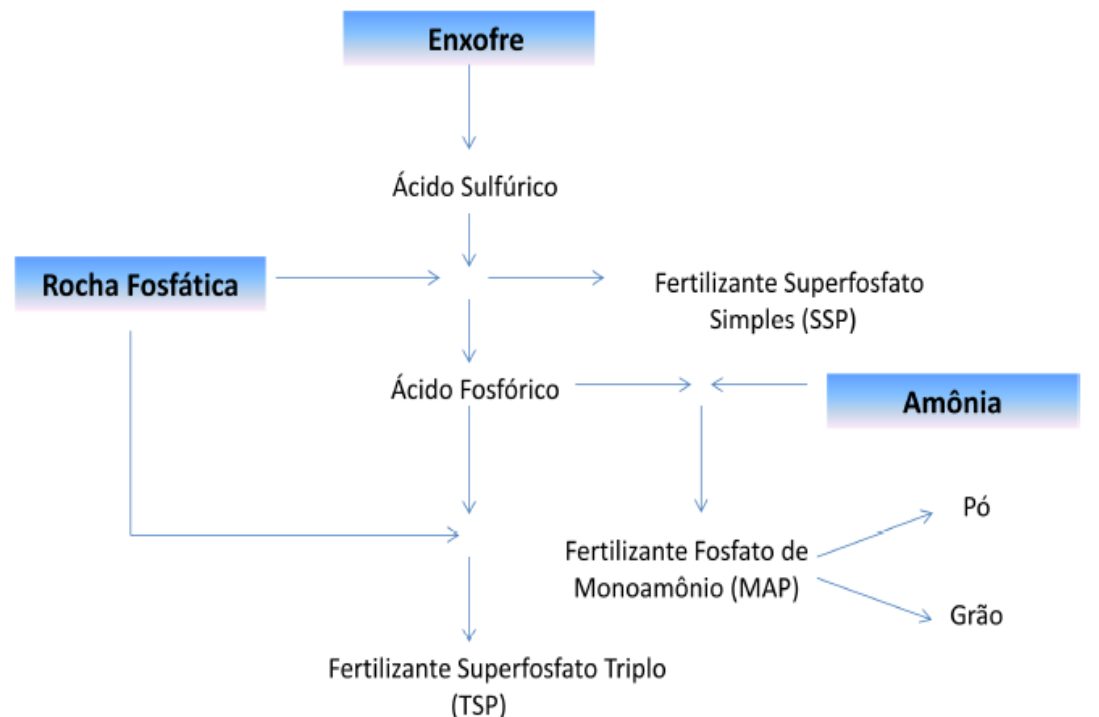

(TSP)

Fonte: ARAUJO, 2013.

No caso dos superfosfatos, a matéria-prima básica é a rocha fosfática, que, atacada por ácido sulfúrico da origem ao superfosfato simples e atacada por ácido fosfórico origina o superfosfato triplo. Prochnow (2012, p.01) ainda melhora a definição para as reações do superfosfato, no caso dos fosfatos amoniados, a matéria-prima básica é o ácido fosfórico, que, reagindo com amônia (NH3) em concentração calculada, origina o fosfatoamono ou diamônico. É importante notar que o ácido fosfórico é obtido pelo ataque da rocha fosfática por ácido sulfúrico, nesse caso utilizado em concentração superior àquela empregada na produção do superfosfato simples.

A química envolvida no processo é muito complexa, principalmente pela variação das impurezas presentes na rocha, bem como, temperatura e concentração do ácido, relação da dosagem ácido e rocha e tamanho das partículas da rocha (RODRIGUES, 2002).

A granulação deste superfosfato simples que irá se transformar nos produtos 00-21-00 ou 03-17-00, serão disponibilizados para as fábricas misturadoras de fertilizantes. Para isso é necessário definir o que seria granulação, e qual sua 
finalidade dentro do processo produtivo de fertilizante. De acordo com SINDEN, (2010 p.02).

Granulação é o nome dado a um tipo de operação que é incluída na área das operações unitárias chamada "size enlargement" (aumento de tamanho).

Existem vários nomes para os processos envolvidos nesta área e realmente faltam definições que sejam aceitas universalmente. Por exemplo, no "5ㅇ․ Simpósio Internacional Sobre Aglomeração", houve uma discussão ativa sobre a utilização da palavra "Aglomeração", onde um percentual significativo dos participantes foi a favor da substituição desta palavra por outra "Agregação".

Na maioria dos casos o formato da partícula formada é esférico, mas em muitos processos o produto apresenta um formato cilíndrico, como um comprimido ou em qualquer outra forma geométrica regular.

Diante destas informações, há a necessidade de mostrar o processo produtivo de fertilizante, para entender o objeto de estudo do trabalho.

A granulação ainda pode ser definida como uma mistura de matérias-primas alimentadas com o material reciclado (retorno do processo produtivo), onde pode haver reação química ou não.

Rodrigues (2002), define que o processo da granulação acontece de duas maneiras complementares, pelo resultado do movimento de rotação dos chamados centros de granulação e também pelo preenchimento de espaços entre as partículas com líquidos. Este processo descrito ocorre dentro de um tambor rotativo chamado de granulador.

Existem alguns fatores que devem ser observados durante o processo de granulação, que é a qualidade da matéria prima e variação de insumos dentro do tambor rotativo, aliado a velocidade de rotação, tempo de residência e alterações feitas pelo operador durante o processo.

Para a produção do fertilizante granulado, devem ser seguidos parâmetros que estão dispostos no decreto no 4954 de 2004, onde este dispõe da inspeção e fiscalização da produção e comércio de fertilizantes em atendimento a legalidade da legislação. Este decreto estabelece limites que devem ser seguidos durante o processo produtivo.

O processo de granulação tem um importante papel na produção de fertilizantes. Araújo (2013) demonstra esta importância, onde os fertilizantes podem ser produzidos em forma de pó, líquido ou granulados, mas o processo de fabricação dos fertilizantes fosfatados do tipo granulado passará por etapas de aumento granulométrico ao longo da cadeia produtiva.

Ainda segundo Araujo (2013, p.15):

Este aumento granulométrico beneficia a absorção dos nutrientes pelas plantas, uma vez que os nutrientes são disponibilizados lentamente, se intensificando durante a irrigação. Além disto, o manuseio para a formulação de 
composições específicas em unidades misturadoras é beneficiado ao trabalhar com grânulos e não pó em virtude da facilidade de mistura.

Desta forma o presente estudo visa a mostrar que durante o processo de granulação existem muitas variações e problemas, estes dependendo do grau, afeta muito a produtividade, gerando perdas e descontrole operacional muito grande, ocasionando paradas que atrapalham o processo produtivo.

Estes problemas devem ser tratados e corrigidos o mais breve possível para que o processo de produção de fertilizantes seja o mais estável e tenha um controle operacional eficiente, reduzindo perdas, paradas, descontroles, ou seja, um processo otimizado que garanta qualidade e preço competitivo do fertilizante produzido, ponto essencial para os clientes e as indústrias.

\section{METODOLOGIA DA PESQUISA}

A metodologia de pesquisa utilizada é a quantitativa, onde serão mostrados dados reais do processo produtivo. É um estudo de caso real de uma situação vivida na JFA Fertilizantes.

Foram coletados dados, elaborando um banco de dados para analisar uma situação vivenciada em 2015 , mostrando uma grande perda em produção através de grandes quantidades de horas paradas ocasionadas por uma calha mal dimensionada na unidade de granulação.

Através de estudos, análises de tabelas e gráficos, verificações em campo, atuação da engenharia de processos e de produção, foi possível observar que seria possível ter um aumento de produção da unidade de granulação. Este aumento viria através da diminuição das perdas ocasionadas pelas horas paradas por obstrução da calha de descarga do granulador.

Através dos dados analisados foi possível traçar ações para trabalhar no problema descrito, definindo um objetivo que seria a diminuição das horas paradas da unidade em função da obstrução da referida calha.

As perdas analisadas, bem como os ganhos obtidos através da implantação das ações estabelecidas pela equipe de engenharia de processo e produção, podem ser visualizadas nos tópicos abaixo.

\section{RESULTADOS E DISCUSSÕES}

\section{ETAPAS DE PRODUÇÃO DOS FERTILIZANTES GRANULADOS}

O fertilizante NP é produzido da seguinte forma. Ataque do ácido sulfúrico na rocha fosfática ultrafina, está sendo obtida através da flotação da rocha fosfática na usina de beneficiamento de minério para aumentar sua concentração de P2O5, viabilizando o comércio e utilização da mesma.

A rocha ultrafina é bombeada via miniproduto e armazenada em tanques em uma unidade de filtragem. Após a filtragem desta rocha a mesma é utilizada para a produção do SSP pó (superfosfato simples). É neste processo onde se tem a 
reação do ácido sulfúrico com a rocha fosfática ultrafina. Agora este SSP produzido é uma matéria prima para a produção de fertilizante granulado.

O processo de produção é simples, porém utiliza-se de reações químicas para sua produção. É feito uma polpa (mistura de água com a rocha ultrafina) com aproximadamente $70 \%$ de concentração de sólidos onde a mesma é bombeada para um reator malaxador, neste, adicionado o ácido sulfúrico e através da reação obtida entre o contato do ácido com a polpa é gerado o SSP. Os gases gerados por este processo são succionados para um sistema de lavagem de gases e neste processo é produzido o ácido fluossilíssico, que após sua geração é utilizado no processo de preparação da polpa substituindo a água utilizada e melhorando as reações com o ácido sulfúrico.

O SSP produzido é armazenado em um galpão para passar também por um processo de cura, onde fica por um período de no mínimo vinte e quatro horas (24h). Neste intervalo de tempo até sua alimentação da unidade de granulação, ainda tem reações acontecendo. Após este tempo, o SSP produzido é alimentado na unidade de granulação.

Este SSP é alimentado através de uma correia transportadora e direcionado ao tambor rotativo chamado de granulador, onde é feita a adição de vapor de água e de outros insumos como (amônia e ácidos para fixação do nitrogênio, utilização de cal hidratada para diminuição de acidez e TSP para aumento de P2O5 solúvel).

Dentro do granulador ocorrem as reações e a formação dos grânulos através da rotação do mesmo e o tempo de residência do fertilizante em seu interior. Após o processo de granulação, o fertilizante granulado passa pelo processo de secagem, para retirada de umidade, peneiramento para classificação do fertilizante, moagem para diminuir o tamanho dos grânulos grossos separados durante o peneiramento que voltam para o processo como reciclo e resfriamento etapa para diminuir a temperatura do produto quem também auxilia na diminuição do empedramento durante a etapa de estocagem. Estas etapas são necessárias para obter o produto com as características físico-químicas desejáveis e qualidades estabelecidas por legislações vigentes.

Após estas etapas de produção, o fertilizante produzido na unidade de granulação é enviado ao galpão de estocagem para ser expedido ao consumidor final que são as fábricas misturadoras de fertilizantes.

\section{ESTUDO DE CASO: PROBLEMAS ENCONTRADOS E SOLUÇÕES IMPLEMENTADAS}

O processo de geração dos grânulos como dito anteriormente é realizado dentro do granulador rotativo.

Para realização desta atividade é necessário um operador ficar o tempo todo no granulador, fazendo as alterações necessárias nos insumos e matérias primas durante o processo produtivo, além de visualizar a formação do grânulo para ter um produto dentro da especificação e qualidade pré-estabelecidas.

Para que o fertilizante passe para o processo de secagem, etapa após a granulação, o mesmo é direcionado para o secador através de uma calha. 
É neste local que o estudo e o trabalho foi realizado. Este lugar também se tem uma temperatura acima da temperatura ambiente, um esforço físico muito grande para limpeza da calha onde o produto é descarregado. Esta impregnação de material na calha é inerente ao processo produtivo, pois com adição de água, vapor, reações com amônia, ácido sulfúrico para a formação do grânulo, geram umidade, bem como acidez, processos que contribuem para incrustação do produto na referida calha.

Além da incrustação que normalmente já se tem devido à característica do produto, com a temperatura elevada, incidência de calor na calha, a dificuldade de limpeza da mesma só aumenta. Isto contribui para a obstrução em vários momentos durante a produção, um trabalho intenso e desgastante durante o turno de trabalho.

O presente estudo irá mostrar a quantidade de horas paradas para limpeza na calha de descarga do granulador no ano de 2015. Também será feito um comparativo com as obstruções ocorridas em 2016 após a implementação de melhorias durante a parada anual da fábrica de fertilizantes neste referido ano.

Entre as várias melhorias realizadas em toda unidade de granulação, destaca-se o foco na calha de descarga do granulador. Foi feita uma mudança do ângulo de inclinação da mesma, mudança do layout e de tamanho, com o intuito de diminuir as incrustações, bem como as obstruções, além de facilitar a limpeza e atuar na melhoria ergonômica do operador durante o seu trabalho.

A calha existente no ano de 2015 era muito comprida, tinha incidência grande de fogo/calor da fornalha, necessário para secar o produto. $\mathrm{O}$ operador não conseguia realizar a limpeza manual completamente da mesma, esta só era realizada em sua totalidade com a parada da unidade, gerando perdas produtivas e descontinuidade operacional.

Com as mudanças propostas, outro ganho que iria acontecer seria o de criar uma a pressão negativa no interior da fornalha, visto que existia uma pressão positiva de mais de $20 \mathrm{~mm}$ de $\mathrm{H} 2 \mathrm{O}$. Com isso, tinha um sopramento de produto e gases quentes na face do operador durante a operação do granulador e a limpeza da calha. Esta atividade além de ser desgastante era realizada inúmeras vezes durante as $24 \mathrm{~h}$ de operação e não era efetiva porque a limpeza não era realizada completamente.

É importante ressaltar que além da mudança do layout, também foram realizados estudos e testes em 2015 observando que a instalação de mantas de borrachas também ajudava na diminuição da impregnação de produto na calha. Além de mantas de borrachas, também ocorreu a instalação de placas de polietileno neste local.

Estas ações propostas e realizadas foram sugeridas através de vários estudos, trabalhos em equipe, utilizando ferramentas de resolução de problemas como MASP, PDCA e implementações de planos de ação durante o período estudado.

Com as ações realizadas, alguns ganhos são observados já no primeiro mês de operação da unidade em 2016. Após a parada para manutenção da unidade de granulação, foi observado um ganho de aproximadamente $60 \%$ em horas paradas por obstrução na calha neste primeiro mês. Com a diminuição da quantidade de limpeza, o operador tem uma melhora significativa no seu 
rendimento, podendo verificar e realizar ações nos processos de produção o que antes era mais difícil. Agora também é possível realizar melhorias na área onde antes não era, visto que na maioria do tempo o mesmo estava envolvido na limpeza da calha.

No ano de 2015, o operador além de produzir tinha que disponibilizar parte do seu tempo a um trabalho de limpeza que não agregava valor nenhum, mas era necessário para tentar diminuir horas paradas da unidade.

Os operadores reclamavam muito com relação à limpeza desta calha, aliado a isso, tinham-se idas com frequências maiores ao ambulatório da empresa para tomar medicamento para dores, problemas de saúde como dores na coluna, afastamentos, etc., problemas de saúde que nenhuma empresa deseja.

A mudança realizada, não acabou com a tarefa de limpeza, porém facilitou e muito este processo. Foi possível observar os ganhos de melhor qualidade de vida para o operador que trabalha no granulador, ganhos operacionais com uma continuidade maior de operação, aumento da produção além do ganho financeiro que é de extrema importância.

Tem-se também a diminuição de retrabalho, pois uma unidade de granulação com uma continuidade operacional maior tem-se menos descontroles, menor variação de processo e um produto sendo feito com uma qualidade maior, diminuindo o seu reprocesso.

Estes ganhos são perceptíveis observando o Gráfico 1, que faz um comparativo de horas paradas apenas por obstrução da calha do granulador entre os anos de 2015 e 2016.

Em 2015 se teve em média 12h paradas por mês ocasionadas pela obstrução da calha. Com as mudanças realizadas em 2016, esta quantidade caiu para em média $2 \mathrm{~h}$ por mês, sendo que em dois meses do ano não foi registrado parada na unidade por obstrução neste local, ou seja, um ganho excelente.

Gráfico 1 - Comparativo de horas paradas nos anos 2015 e 2016

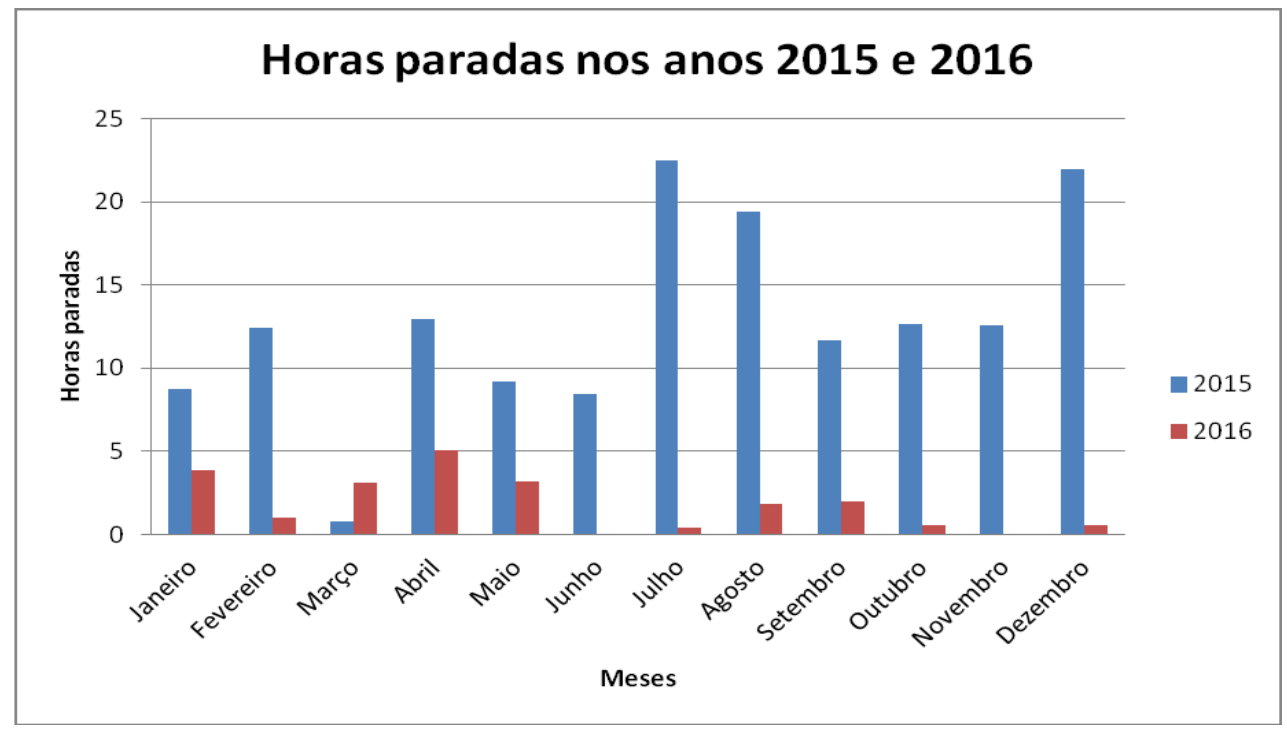

Fonte: elaborado pelos autores 
No Gráfico 2, também é possível observar a quantidade de perdas de produção nos anos de 2015 e 2016. Com a mudança, ocorrida em 2016 pode observar um ganho em torno de 76\% em relação a 2015.

Estes ganhos são fundamentais para uma empresa onde se tem metas de produção a serem cumpridas mensalmente ou anualmente. Além disso, é extremamente fundamental uma unidade onde sem tem menos paradas e maior continuidade operacional.

Gráfico 2 - Comparativo de perdas nos anos de 2015 e 2016

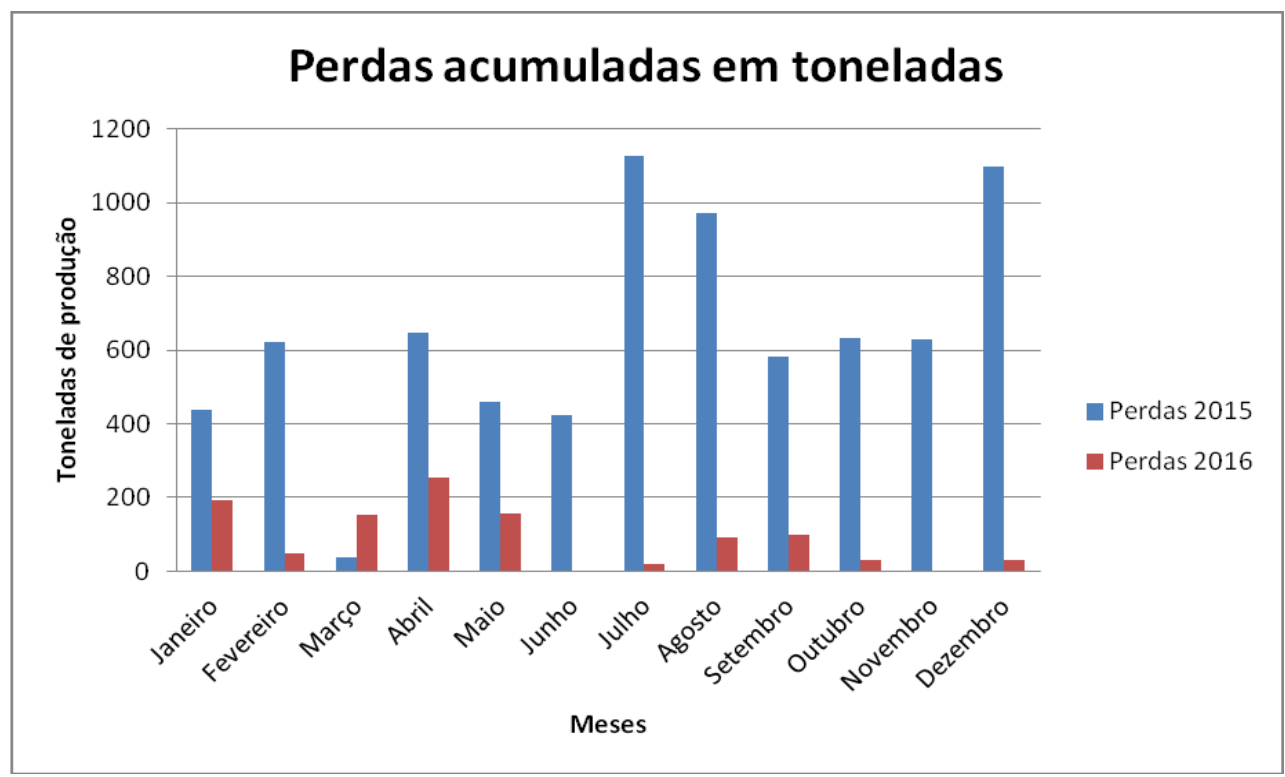

Fonte: elaborado pelos autores

Não está sendo mostrado aqui neste trabalho os problemas que muitas vezes são gerados e ocorridos no retorno da unidade. Ocorrem quebra de ritmo na produção, descontrole operacional, há uma necessidade de aquecer todo o sistema, na maioria das vezes é gerada grande quantidade de reciclo o que dificulta o retorno de operação da unidade.

Estas perdas não estão sendo mensuradas. As perdas e ganhos descritas no presente trabalho estão relacionadas apenas ao problema da obstrução.

No ano de 2015, em média houve perda de 640 toneladas de fertilizantes por mês, com um comparativo de 2016, esta perda caiu muito, para média de 90 toneladas de fertilizantes, o que mostra um ganho de aproximadamente $76 \%$.

Hoje, ainda se tem perdas, estas ainda estão relacionadas à geração de blocos no interior do granulador que também dará um bom trabalho para ser feito futuramente.

Financeiramente também é possível mensurar o tamanho dos ganhos. No ano de 2015, realizando uma avaliação apenas com horas paradas, teve se perdas acumuladas em aproximadamente $\mathrm{R} \$ 1.150 .000,00$, uma média de $\mathrm{R} \$ 96.000,00$ por mês. Podemos observar ainda no Gráfico 02, que em dois meses do ano Junho e Novembro, não ocorreram paradas da unidade por obstrução da calha.

Após o trabalho proposto e realizado, observam-se ainda perdas, porém estas bem menores. No ano de 2016, esta perda ficou bem abaixo em relação a 
2015 , totalizando perdas na ordem de $\mathrm{R} \$ 161.600,00$ com média de $\mathrm{R} \$ 13.500,00$ por mês, fato que pode ser observado no Gráfico 3.

Vale deixar uma observação que em março de 2015, houve uma parada anual da unidade, operando apenas cinco dias do mês ponto este onde a perda de 2015 é menor em relação ao mesmo período de 2016.

Gráfico 3 - Comparativo de perdas em R\$ nos anos de 2015 e 2016

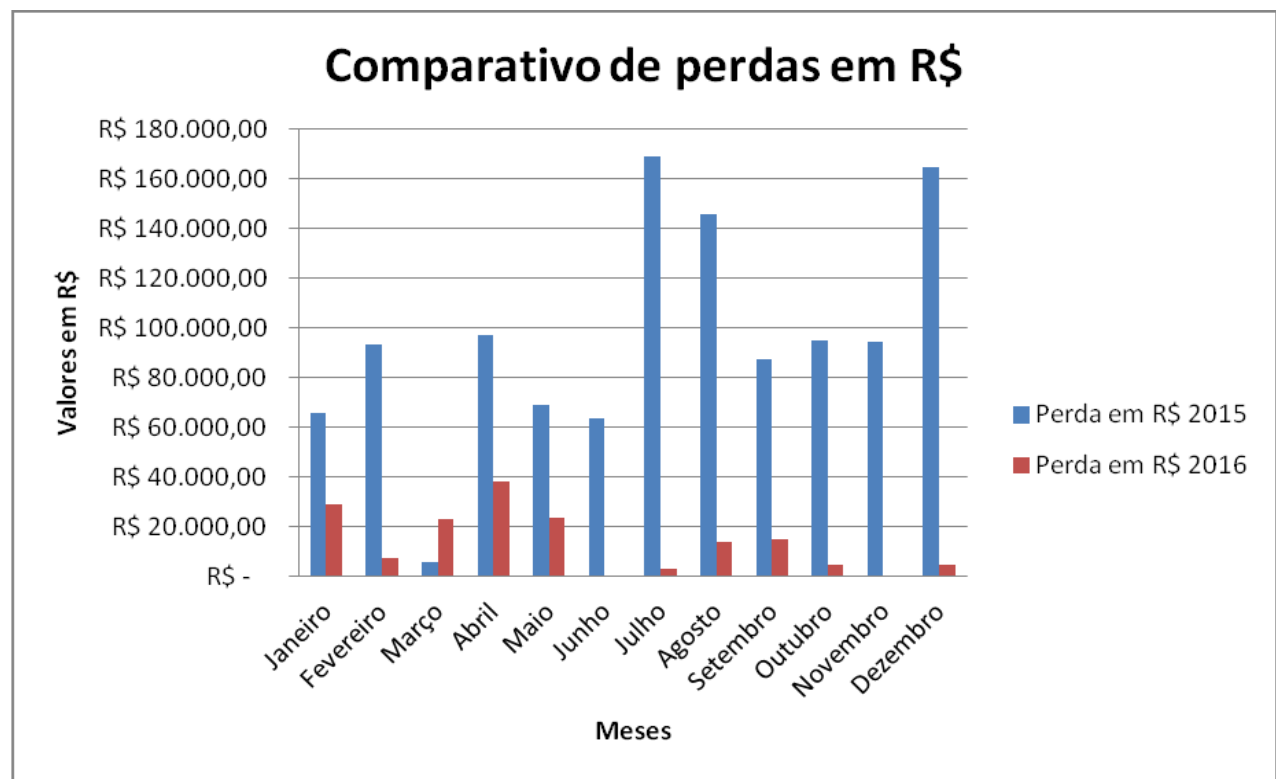

Fonte: elaborado pelos autores

As perdas diminuíram consideravelmente e os ganhos são fáceis de visualizar através dos gráficos mostrados no trabalho. Outro ganho muito grande que não foi evidenciado profundamente no trabalho foi para o operador que trabalha no granulador.

Na calha que estava instalada em 2015 o operador há quase todo instante tinha que realizar a limpeza da mesma e a dificuldade era enorme pela incidência muito grande de calor. O material que escoava na calha era fundido pela alta temperatura, grudava e sua limpeza se tornava pior. O operador como não conseguia limpar completamente, deixava a calha sujar até o ponto da obstrução, aí, com a unidade parada era feito a limpeza geral.

Esta limpeza era desgastante visto que pelo comprimento da calha, pela sujeira acumulada com o tempo, a dificuldade aumentava consideravelmente.

Com a mudança do layout que foi feito, a calha ainda tem incidências de calor, em função do local de instalação. Porém, durante o trabalho executado, também foi instalado uma parede de concreto refratário na parte traseira da calha, diminuindo a incidência de calor na mesma, com isto a diminuição da incrustação, facilitando e muito a sua limpeza.

Além da mudança do layout, houve a alteração do ângulo de inclinação o que aumentou consideravelmente a facilidade de escoamento do produto. Com a inclinação maior da calha, o produto ao ser descarregado do granulador já é direcionado em quase sua totalidade para o secador. Apenas uma pequena parte 
do produto que ainda impregna na mesma. Ergonomicamente para o operador esta mudança foi muito boa.

Além disso, foram confeccionadas mantas de borrachas reservas para esta calha e também a mudança da forma de instalação da mesma. Quando ocorrer uma necessidade de substituição destas mantas durante a operação a troca é feita com uma maior rapidez. No ano de 2015 não se tinha mantas reservas e para a instalação e substituição da mesma deveria esperar a diminuição de temperatura, pois a troca só era possível quando entrava no interior da fornalha para a substituição.

Pode ser observado no Gráfico 4 o ganho gigantesco que se teve através do trabalho proposto. Perdas que no ano de 2015 ficaram acima de um milhão de reais, no ano de 2016 a mesma caiu em torno de cento e sessenta mil reais.

Gráfico 4 - Diferença de perdas em R\$ nos anos de 2015 e 2016

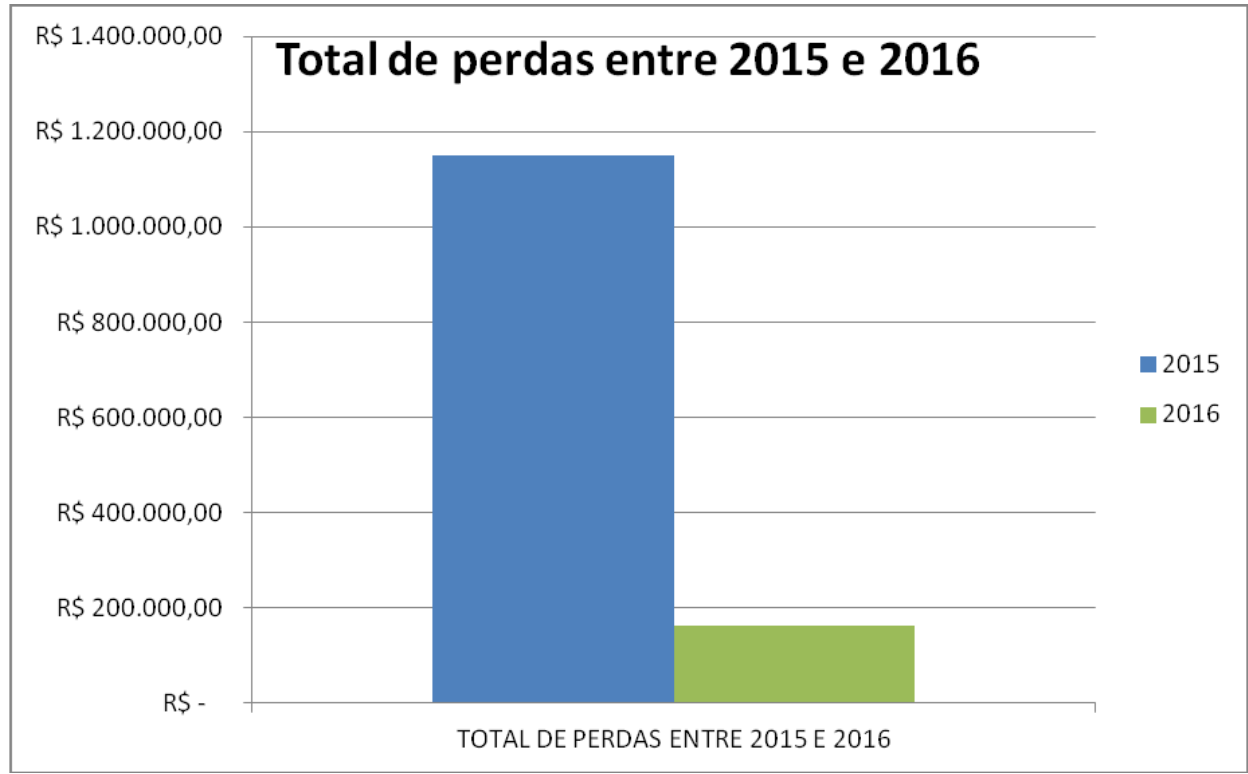

Fonte: elaborado pelos autores

Com as mudanças realizadas, foi possível mudar a forma de instalação e manutenção destas mantas, a substituição agora pode ser feita sem a necessidade de entrar na fornalha, diminuindo o tempo de parada da unidade, consequentemente ganhos de produção e financeiro.

Conforme mencionando anteriormente, os principais ganhos ocorreram em virtude da mudança do layout e ângulo de inclinação da calha.

A principal mudança no layout foi o aumento do diâmetro do duto de descarga e mudança da entrada de gases para o secador, melhorando a secagem do produto e também o escoamento do fertilizante para o secador. Estas mudanças podem ser observada nas Figuras 2 e 3.

Estes fatores foram fundamentais para a concretização da proposta estabelecida. 
Figura 2 - Calha com ângulo de 57은

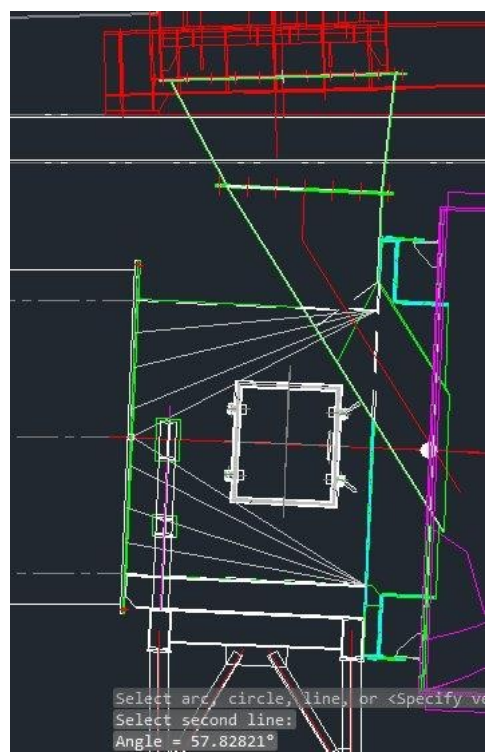

Fonte: elaborado pelos autores
Figura 3 - Calha com ângulo de 65은

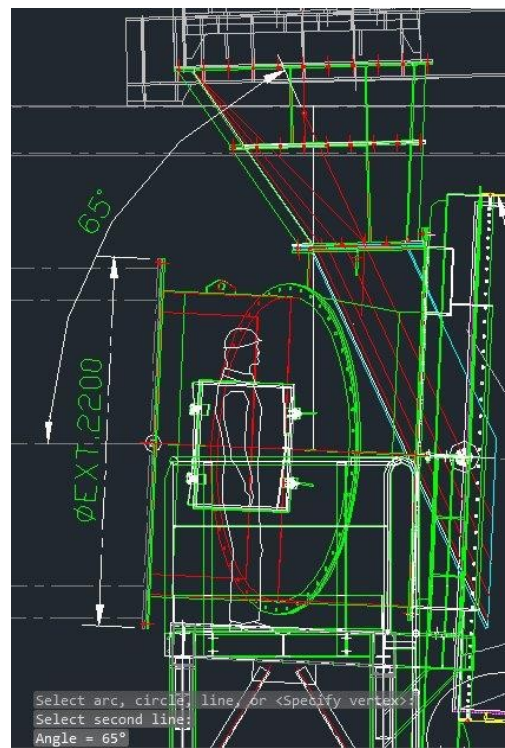

Fonte: elaborado pelos autores

\section{CONSIDERAÇÕES FINAIS}

É possível observar nos resultados mostrados no trabalho que a proposta estabelecida foi alcançada e superada.

As reduções de horas paradas da unidade causadas pela obstrução da calha, com certeza melhoraram a produção, visto que também, melhorou a continuidade operacional e aumento de produção contribuindo grandemente no resultado. Uma unidade de produção de fertilizantes com várias paradas corretivas é uma fábrica que possivelmente terão seus resultados abaixo do esperado em produção, produtividade e qualidade.

A qualidade é diminuída porque no momento em que se para uma unidade de granulação, a dosagem de insumos ou variação na alimentação da matéria prima irá afetar os resultados. Estas variações atrapalham a operacionalização das unidades, gerando altos custos e um menor rendimento financeiro para a empresa.

O trabalho proposto teve seu objetivo alcançado, onde foram reduzidas as horas paradas, além de um aumento da produtividade e também aumento da produção comparada com o período proposto, aliado a isso uma melhor condição de operação da unidade e melhores condições de operações para os operadores que trabalham na unidade de granulação 


\title{
Reduction of stopped hours in the granulation stage: a case study of the granulator discharge choke obstruction
}

\begin{abstract}
The search for increased productivity and the constant improvement of the process have been the focus of large companies to stay in the market. In view of this, the various organizations seek to optimize their processes by applying improvements that may be small, but that in the end help in the goals of the company. In this context, the objective of this study is to show that with the reduction of stopped hours due to obstruction of the granulator trough, there are gains of production in the granulation unit, greater operational continuity that is fundamental in a fertilizer factory and, consequently, less operational controls During the production process. The idea of the present study arose from the analysis of the number of hours stopped by obstruction of the discharge chute of the granulator. From the analysis of the stopped hours, observation in the field of the problems caused by the obstruction of the channel, it was possible to outline actions to eliminate / mitigate this problem. Obstruction of the gutter caused some problems, such as loss of production and operational discontinuity. In the study carried out, the actions taken were very effective, reducing the hours stopped, increasing gains in production and losses losses after their implementation. It is very important to note also that the improvement achieved brought in addition to operational gains, also gains for workers in quality of life by the decrease of the manual labor exhausting. The granulation unit began to operate with a much higher operational continuity in the observed periods.
\end{abstract}

KEYWORDS: Productivity. Fertilizers. Granulator. 


\section{REFERÊNCIAS}

ARAUJO, M. M., Análise do processo de secagem de fertilizantes em secador rotativo, Ouro Preto. 2013.

BRASIL, 2004. Decreto no4954, Dezembro de 1980.

FERREIRA, A.C.B. Efeitos da adubação com N, Mo e Zn, sobre a produção e qualidade de grãos e concentração de nutrientes no milho. Viçosa, 1997. 73p. Tese mestrado - Universidade Federal de Viçosa.

PROCHNOW, L. I. Fertilizantes fosfatados: algumas crenças e alguns fatos científicos. 2012. Disponível em:

http://hotsites.cnps.embrapa.br/blogs/redefertbrasil/conteudo/artigos/4.pdf. Acesso em 23 mar. 2016.

RODRIGUES, S. A. Apostila Técnica de produção de fertilizantes. Ultrafértil 2002.

SINDEN, J. Apostila de granulação. Consultoria e assessoria técnica, Copebrás. Catalão, 2010.

SOARES, J. C. Teores de Ferro, Manganês e Cobre no cafeeiro recepado em função de diferentes doses de P2O5. Muzambinho, 2008.

SOARES, M. A. Influência do Nitrogênio, zinco e boro e de suas respectivas interações no desempenho da cultura do milho. Piracicaba, 2003.

2 CONGRESSO BRASILEIRO DE FERTILIZANTES, 2012, São Paulo, 27 Ago. 2012. Disponível em < http://www.anda.org.br/index.php?mpg=06.11.01\&ver=por >. Acesso entre Janeiro e Dezembro de 2016 
Recebido: 24 jul 2017

Aprovado: 16 mar 2018

DOI: 10.3895/gi.v14n1.6760

Como citar:

GONÇALVES, J. R.; MIRANDA, M. R. da S. Redução de horas paradas na etapa de granulação: um

estudo de caso da obstrução da calha de descarga do granulador. R. Gest. Industr., Ponta Grossa, v

14, n. 1, p. 123-138, jan./mar. 2018. Disponível em: <https://periodicos.utfpr.edu.br/rgi>. Acesso em: XXX.

Correspondência:

Jaziel Rosa Gonçalves

Rua: T27, Qd.44, Residencial Gran Bueno, Ap.503, Goiânia, Goiás, Brasil.

Direito autoral: Este artigo está licenciado sob os termos da Licença Creative Commons-Atribuição 4.0

Internacional.

(c) (i) 